\title{
A nonlinear damping control for the vibration mitigation of the benchmark highway bridge
}

\author{
Gisela Pujol ${ }^{1}$, Leonardo Acho ${ }^{1}$, Francesc Pozo ${ }^{1, *, \dagger}$ and José Rodellar ${ }^{2}$ \\ ${ }^{1}$ CoDAlab, Departament de Matemàtica Aplicada III, Escola Universitària d'Enginyeria Tècnica Industrial de Barcelona \\ (EUETIB), Universitat Politècnica de Catalunya (UPC), Comte d'Urgell, 187, 08036 Barcelona, Spain \\ ${ }^{2}$ CoDAlab, Departament de Matemàtica Aplicada III, Escola Tècnica Superior d'Enginyers de Camins, Canals $i$ Ports de \\ Barcelona (ETSECCPB), Universitat Politècnica de Catalunya (UPC), Barcelona, Spain
}

\begin{abstract}
SUMMARY
Active, passive and semi-active controls have been extensively considered to improve the protection of structures against earthquakes. In this paper, we present a new nonlinear damper, which is then applied to a three-dimensional benchmark structural control problem for seismically excited highway bridge. The main feature of the proposed controller is the simplicity in formulation, design and implementation. It is based on using a passive static hyperbolic function depending only on the base velocity. This function ensures energy dissipation capability with always bounded control force. The performance indices show that the proposed controller behaves satisfactorily and with a reasonable control effort. Copyright (C) 2009 John Wiley \& Sons, Ltd.
\end{abstract}

KEY WORDS: highway bridge; structural control; nonlinear damping; MR dampers

\section{INTRODUCTION}

Highway bridges are critical infrastructures, which require particular seismic protection. It has been demonstrated that passive, semi-active and active control systems installed in parallel with isolation bearings are capable of reducing excessive displacements of bearings or significant damage to bridge piers [1-4]. In this direction, the structural control community is devoting efforts to investigate the effectiveness and applicability of systems for vibration mitigation of highway bridges.

\footnotetext{
*Correspondence to: Francesc Pozo, Departament de Matemàtica Aplicada III, Escola Universitària d'Enginyeria Tècnica Industrial de Barcelona (EUETIB), Universitat Politècnica de Catalunya (UPC), Comte d'Urgell, 187, 08036 Barcelona, Spain.

†E-mail: francesc.pozo@upc.edu

Contract/grant sponsor: CICYT; contract/grant number: DPI2005-08668-C03-01
} 
To meet this objective, a benchmark structural control model for highway bridges was developed through the sponsorship of the American Society of Civil Engineering (ASCE) Committee on structural control to provide systematic and standardized means by which competing control strategies can be evaluated [5-7]. This benchmark is a three-dimensional finite element model of the newly constructed $91 / 5$ highway bridge located in Orange County of Southern California, USA. Basically, this bridge is a continuous two-span bridge with two abutments skewed $33^{\circ}$ and with a deck for four-lane highway supported by a bent column. Furthermore, this 430 degrees-of-freedom benchmark model is able to capture nonlinear effects of the bridge such as inelastic moment-curvature behavior of columns and shear-displacement relationship of bearings, among some others. To facilitate direct comparison of the relative merits of various control strategies, a set of 21 evaluation criteria is defined along with several prescribed ground motion excitations.

Other benchmark models have been proposed by the ASCE structural control committee for assessing control strategies in buildings under earthquake and wind loads [8-11], cablestayed bridges [12,13] and smart base-isolated buildings [14-17].

Control of structures can be classified in three groups: (a) passive control; (b) active control; and (c) semi-active control. A passive control system utilizing the local motion at a point where the control system is connected to the structure to produce control forces is well understood and widely accepted worldwide. The main practical and implementation advantage is the simplicity and the reliability, along with the fact that they are normally based on clear physical principles. The main drawback is that they are built carefully tuned for specific operating conditions and cannot adapt to changes and unknown disturbances. Active and semi-active systems are dynamic controllers requiring sensors and actuators in a closed loop control scheme. Active control has the conceptual ability to precisely supply the force commanded by a control algorithm. The price to pay is the need of appropriate actuators, the availability of energy supply and the demand of a careful formulation and design work to ensure stability and avoid unfeasible input and output signals. Semi-active control can be designed to approach the performance of active controllers without requiring large power consumptions and being inherently stable. In the numerical simulations in [7], where passive, active and semi-active sample controllers are implemented, it is shown that the sample passive controller is unable to reduce the peak and norm controlled responses with respect to the uncontrolled bridge structure.

In this paper, a new control approach is presented and numerically tested through its application to the benchmark highway bridge. Inspired by passive control, the main motivation is to supply a damping capability with a simple and bounded control law. This is done by using a passive function depending only on the local velocity. Simplicity in the formulation and boundedness is ensured by proposing a static hyperbolic function.

The organization of this paper is as follows. In Section 2, a new hyperbolic passive damper is proposed together with a stability proof of the closed-loop system. Possible realizations of this controller are also discussed in this section, particularly as a semi-active scheme using magnetorheological (MR) fluid dampers. The benchmark structural control problem for a seismically excited highway bridge is briefly presented in Section 3. Numerical experiments to analyze the performance of the proposed controller are presented in Section 4. Final comments are given in Section 5. 


\section{HYPERBOLIC LOCAL CONTROL}

\subsection{Control objective and design}

Let us consider a single degree-of-freedom system with mass $m$, stiffness $k$ and damping coefficient $c$ :

$$
m \ddot{x}+c \dot{x}+k x=-m \ddot{u}_{\mathrm{g}}+u
$$

where $\ddot{u}_{\mathrm{g}}$ denotes the ground acceleration which is assumed bounded; that is, there exists a constant $F$ such that $\left|\ddot{u}_{\mathrm{g}}\right| \leqslant F$ for all $t \geqslant 0$. Finally, $u$ is the control force supplied by an appropriate device.

We seek for a controller exhibiting the following features:

(a) To be a static controller employing only local velocity information between the two points where the controller is connected.

(b) To be an admissible controller, that is, when the seismic excitation is not present $\left(\ddot{x}_{\mathrm{g}}=0\right)$, the closed-loop system is asymptotically stable.

(c) Ensure that, when the seismic excitation is present, all the trajectories of the closed-loop system are bounded.

Consider a passive function $g: \mathbb{R} \rightarrow \mathbb{R}, g \in \mathscr{C}^{1}$, that is, a function such that $g(x) \cdot x \geqslant 0$, $g(0)=0$. Then, we propose a control law with the following structure:

$$
u=-\rho \cdot g(\dot{x})
$$

where $\rho>0$ is a coefficient, and $\dot{x}$ the local velocity between the two points where the controller is connected.

To proof the admissibility of the controller in Equation (2), consider the positive definite Lyapunov function

$$
V(x, \dot{x})=\frac{1}{2} m \dot{x}^{2}+\frac{1}{2} k x^{2}
$$

Its time derivative along any trajectory of the unperturbed $\left(\ddot{u}_{\mathrm{g}}=0\right)$ closed-loop system (1)-(2) yields,

$$
\begin{aligned}
\dot{V} & =m \dot{x} \ddot{x}+k x \dot{x} \\
& =\dot{x}(-c \dot{x}-k x-\rho g(\dot{x}))+k x \dot{x} \\
& =-c \dot{x}^{2}-\rho g(\dot{x}) \dot{x}
\end{aligned}
$$

Clearly $\dot{V} \leqslant 0$. Asymptotic stability of the unperturbed closed-loop system (1)-(2) is concluded after employing the well-known La Salle principle. Utilizing the same Lyapunov function, when the system is perturbed, its time derivative along the trajectories of the closedloop system (1)-(2) is

$$
\begin{aligned}
\dot{V} & =-c \dot{x}^{2}-\rho \dot{x} g(\dot{x})-\dot{x} m \ddot{u}_{\mathrm{g}} \\
& \leqslant-c|\dot{x}|^{2}+|\dot{x}| m F \\
& =-|\dot{x}|(c|\dot{x}|-m F)
\end{aligned}
$$


The above expression is semi-definite negative when $|\dot{x}|>m F / c$, which demonstrates that the trajectories of the perturbed closed-loop system (1)-(2) are bounded.

Therefore, any controller defined by means of a passive function, solves the control objective, as expected. To demonstrate seismic attenuation, let us compare the values of the Lyapunov time derivative in open loop and closed loop, i.e. $\dot{V}_{\mathrm{OL}}$ and $\dot{V}_{\mathrm{CL}}$. From Equation (3),

$$
\dot{V}_{\mathrm{CL}}=\dot{V}_{\mathrm{OL}}-c \dot{x} g(\dot{x}) \Rightarrow \dot{V}_{\mathrm{CL}}<\dot{V}_{\mathrm{OL}}
$$

Define now, for both cases, the transient decay rate as in [18]:

$$
\zeta=\frac{-\dot{V}(x)}{V(x)}
$$

From (5), we deduce that

$$
\zeta_{\mathrm{CL}}>\zeta_{\mathrm{OL}}
$$

Then, the closed-loop system has a larger transient decay rate response than the uncontrolled system and mitigates the seismic disturbance.

Clearly, when $g(\dot{x})=\operatorname{sgn}(\dot{x})$, the signum function, the resulting controller is equivalent to the well-known pure friction damper. When $g(\dot{x})=\dot{x}$, the controller is the classical local proportional velocity control equivalent to a linear damper.

In this work, a different passive function is proposed with the following hyperbolic form:

$$
g(\dot{x})=\operatorname{sech}\left(\frac{\dot{x}}{a}\right) \cdot \tanh \left(\frac{\dot{x}}{a}\right)
$$

where $a>0$ is a design parameter.

Figure 1 plots this function and may help to highlight some nice features in relation to the control objective:

- The value of $g(\dot{x})$ is bounded irrespective of the value of the velocity $\dot{x}$. The maximum control input is prescribed by choosing the gain parameter $\rho$. This boundedness will be a key point later on to ensure the desired stability of the closed loop.

- The maximum absolute value of $g$ is reached for the velocities $\dot{x}= \pm \bar{a}= \pm a \cdot \operatorname{arctanh}(\sqrt{2} / 2)$. This means that the design parameter $a$ can be easily selected to prescribe these velocities. For velocities within the range $\dot{x} \in[-\bar{a}, \bar{a}]$, the response of the controller is like the one of a typical s-shaped nonlinear damper. For velocities beyond this range, the control force smoothly decays. In practice, the value of $a$ can be designed large enough to prescribe an always bounded control force with a certain damping profile within a range of the maximum expected velocities.

\subsection{On practical implementation}

The expression in Equations (2)-(6) defines one way of producing a control force depending on the velocity $\dot{x}$. The simplicity of this expression suggests the possibility of a purely passive implementation if an appropriate device is available. This device should be designed and tuned by selecting the parameters $a$ and $\rho$. The expression in (2)-(6) can be also seen as an active control law, which can be implemented by an appropriate actuator by using only local velocity feedback. 


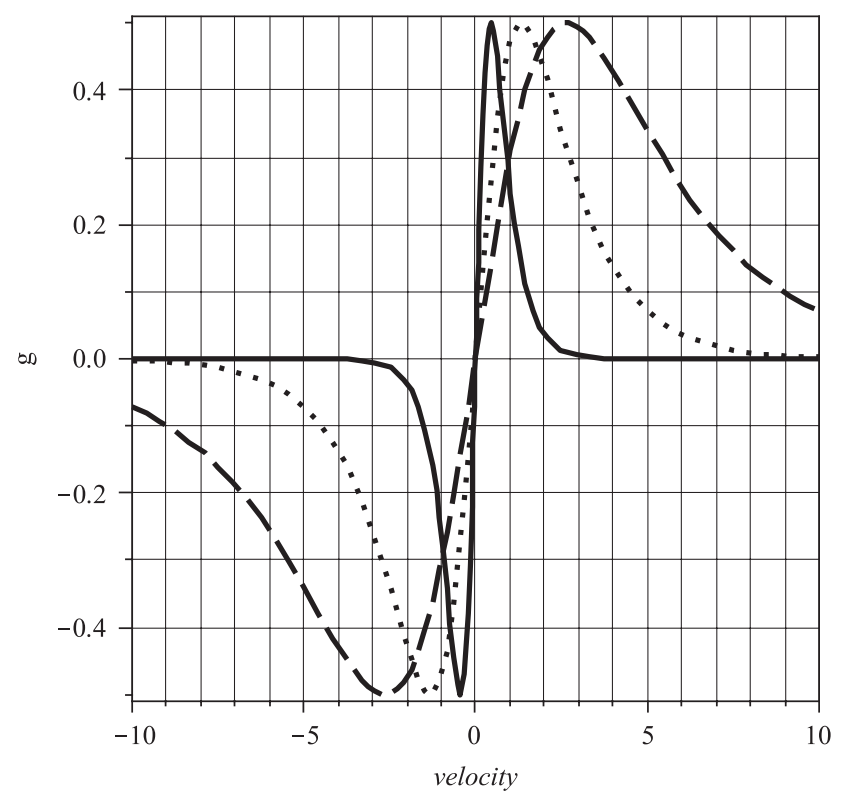

$-\mathrm{a}=3,-\mathrm{a}=0.5, \ldots \mathrm{a}=1.5$

Figure 1. Hyperbolic passive function (6) with $a=0.5, a=1.5$ and $a=3$. The maximum absolute value is obtained for the velocities $\pm a \cdot \arctan h(\sqrt{2} / 2)$.

Between passive and active schemes, the above control law may have a semi-active realization. In this respect, let us consider an MR fluid damper. A phenomenological model of MR dampers, widely used in practice, is based on the Bouc-Wen hysteretic model in parallel with a dashpot $[19,20]$. The equations governing the force produced by this model of MR damper are

$$
\begin{aligned}
& f=c_{0} \dot{x}+\alpha z \\
& \dot{z}=-\gamma|\dot{x}| z|z|^{n-1}-\beta \dot{x}|z|^{n}+A \dot{x}
\end{aligned}
$$

where $\dot{x}$ is the velocity of the device, $z$ is the evolutionary variable and $\gamma, \beta, n$ and $A$ are parameters controlling the linearity in the unloading and the smoothness of the transition from the pre-yield to the post-yield region. The functional dependence of the device parameters on the command voltage $u_{c}$ is expressed as

$$
\begin{gathered}
\alpha=\alpha\left(u_{c}\right)=\alpha_{a}+\alpha_{b} u_{c} \\
c_{0}=c_{0}\left(u_{c}\right)=c_{0 a}+c_{0 b} u_{c}
\end{gathered}
$$

Typically, semi-active implementations of MR dampers operate in such a way that the voltage command signal is either zero or maximum, within a clipped control structure [19] or bang-bang Lyapunov design [21]. This may lead to larger forces when the structure is subject to moderate or small earthquakes. It can be proved that the following smooth command voltage function

$$
u_{c}=\frac{\operatorname{sech}(\dot{x}) \tanh (\dot{x}) \operatorname{sgn}(\dot{x})}{1+|\dot{x}|}
$$




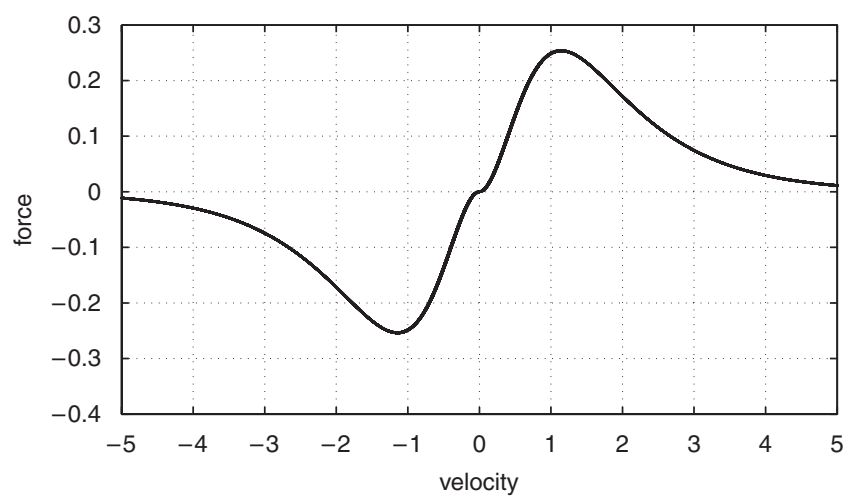

Figure 2. Force-velocity relationship of an MR damper, using the command voltage function in Equation (11).

is able to produce a force-velocity relationship in an MR damper modelled by Equations (7)-(10). The details of the derivation are omitted here, but Figure 2 (obtained with a particular set of parameters) illustrates how the force-velocity of an MR damper resembles the force-velocity relationship shown in Figure 1.

In this paper, the control law (2)-(6) is applied to the benchmark highway bridge described in [5]. Since the main objective of the application is to assess the efficiency of the concept of such stabilizing control law, it is applied in a generic way independently of which particular actuating scheme would be available for the implementation.

\section{BENCHMARK HIGHWAY BRIDGE}

The benchmark structural control problem for a seismically excited highway bridge [5] is employed as an interesting and more realistic example to further investigate the effectiveness of the proposed design approach. This benchmark problem is based on the newly constructed $91 / 5$ highway over-crossing in Southern California, and it is recognized by the ASCE Committee on structural control as a state-of-the-art model developed to provide a computational platform where competing control strategies, including devices, control algorithms and sensors, can be evaluated [5,7].

The benchmark highway bridge is a continuous two-span, cast-in-place pre-stressed concrete box-girder bridge. The Whittier-Ellsinore fault is $11.6 \mathrm{~km}$ to the northeast, and the Newport-Inglewood fault zone is $20 \mathrm{~km}$ to the southwest of the bridge. The bridge has two spans, each of $58.5 \mathrm{~m}$ long spanning a four-lane highway and has two abutments skewed at $33^{\circ}$. The width of the deck along east span is $12.95 \mathrm{~m}$ and it is $15 \mathrm{~m}$ along west direction. The cross section of the deck consists of three cells. The deck is supported by a $31.4 \mathrm{~m}$ long and $6.9 \mathrm{~m}$ high pre-stressed outrigger, which rests on two pile groups. The columns are approximately $6.9 \mathrm{~m}$ high. A plan view of the pile group is shown in Figure 3 . Figure 4 shows the idealized model for the bridge, its approach embankments and pile foundations. 


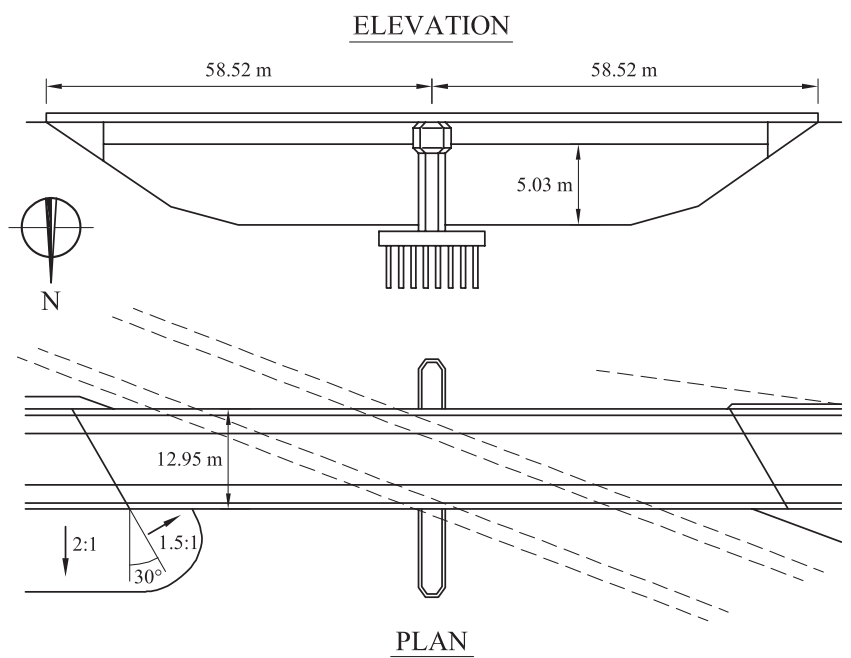

Figure 3. Elevation and plan views of $91 / 5$ over-crossing.

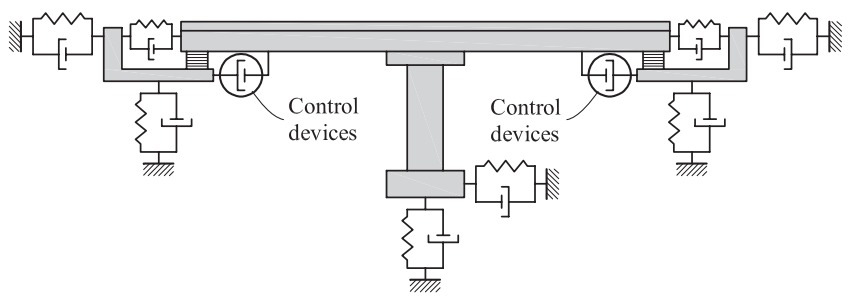

Figure 4. Elevation view of idealized model.

\section{NUMERICAL RESULTS}

\subsection{Parameter tuning}

As can be seen in Equation (6), the proposed control depends on the choice of the parameter $a$, which models the shape of the function $g$ in Equation (2). In order to tune this design parameter, the following study has been carried out. We have computed the evaluation criteria $J_{1}, J_{2}, \ldots$, $J_{16}$ for several values of the design parameter $a$ and for the North Palm Springs earthquake record, which is considered - in our simulations - the most uncontrollable ground motion. Figures 5 and 6 show that for $1.5 \leqslant a \leqslant 5$, all the performance indices are less than or equal to 1 . This way, the designers can choose the design parameter $a$ according to some optimization criteria.

\subsection{Numerical results}

The results of the proposed hyperbolic active control in Equation (2) of the benchmark problem are summarized in Tables I and II. The results are also compared with the performance indices in [7]. The evaluation is reported in terms of the performance indices described in [5]. The controlled benchmark highway bridge is simulated for six earthquake ground accelerations 

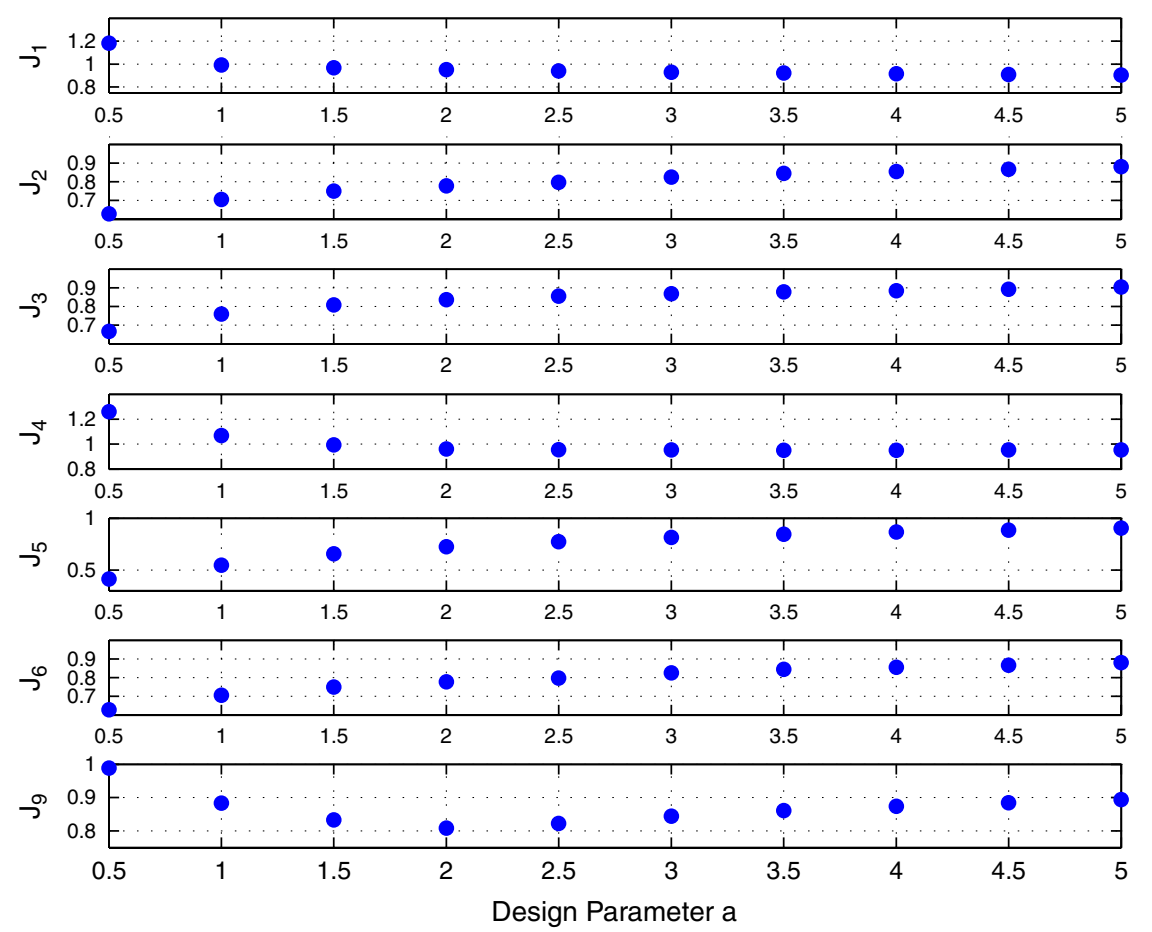

Figure 5. Evaluation criteria $J_{1}, J_{2}, J_{3}, J_{4}, J_{5}, J_{6}$ and $J_{9}$ for several values of the parameter $a$.

defined in the benchmark problem (North Palm Springs, Chichi, El Centro, Northridge, Turkey and Kobe). All the excitations are used at the full intensity for the evaluation of the performance indices. The performance indices larger than one indicate that the response of the controlled highway bridge structure is bigger than that of the uncontrolled bridge structure. The performance indices larger than one in Table I are highlighted in bold.

In this paper, the controllers are placed in eight specific locations, between the end abutments and deck, and making use of the passive scheme of the benchmark. At each location, there are two controllers - one in the $x$ - and one in the $y$-direction. These actuators are used to apply the active control forces to the bridge structure. In this control strategy, both the peak and normed evaluation criteria are smaller than one for all earthquake records. In addition, most of these responses are reduced substantially from the uncontrolled cases.

The peak base shear is reduced between 10 and $20 \%$ in a majority of earthquakes (except North Palm Springs, where this quantity decreases only by $3 \%$ ). The corresponding normed base shear quantities are reduced between 20 and $37 \%$. The reduction in-peak mid-span displacement is between 14 and $27 \%$ whereas the reduction in normed mid-span displacement is between 20 and $37 \%$. Slight reductions in the peak mid-span acceleration between 1 and $9 \%$ are achieved for all earthquake records when compared with the uncontrolled case, although conversely the corresponding normed quantities are significantly reduced between 11 and $25 \%$. It is also interesting to note that the application of the proposed active control can result in the reduction of the ductility factor (peak or normed) up to $51 \%$. Thus, damage in the bridge is significantly minimized. 

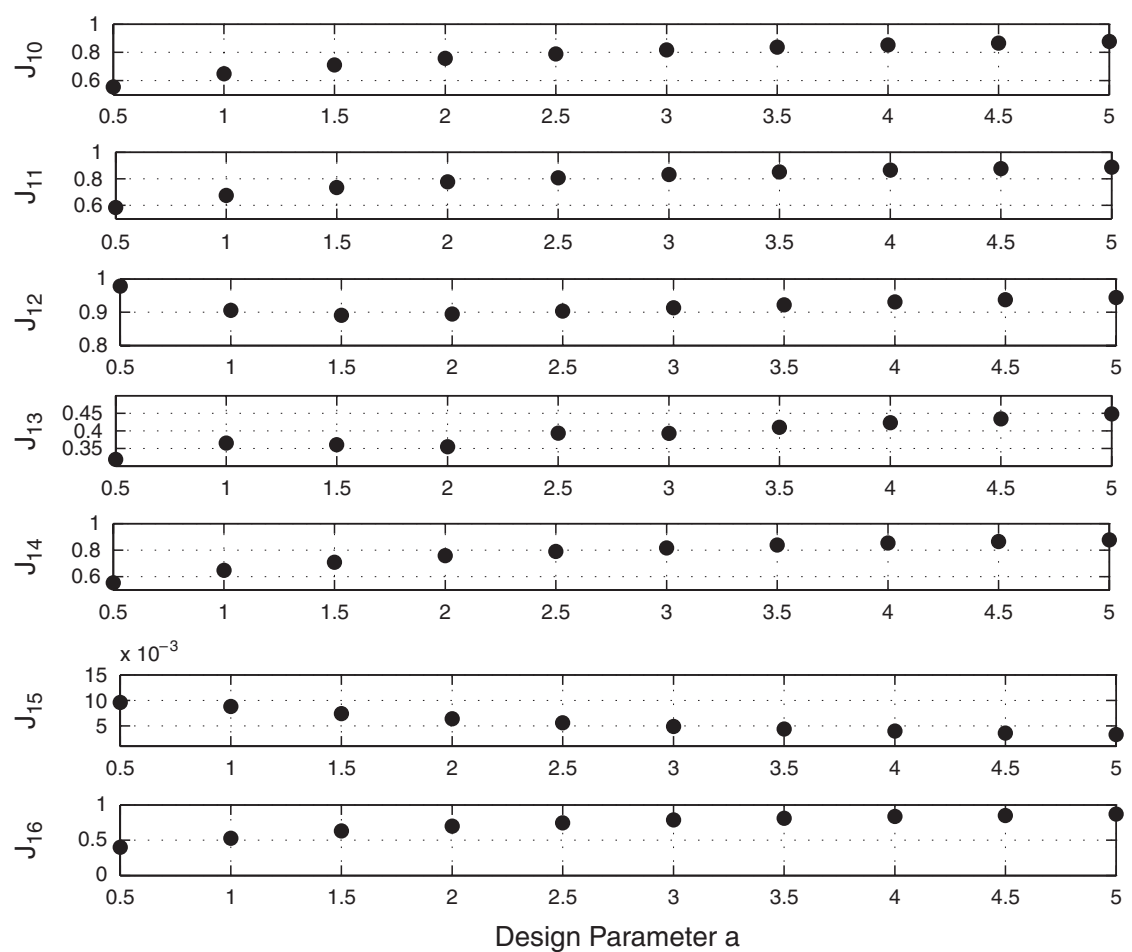

Figure 6. Evaluation criteria $J_{10}, J_{11}, J_{12}, J_{13}, J_{14}, J_{15}$ and $J_{16}$ for several values of the parameter $a$.

Table I. Evaluation criteria for the proposed hyperbolic nonlinear damper in Equations (2)-(6) compared with sample passive, semi-active and active controllers in [7] using North Palm Springs earthquake (1986), with $a=1.5$ and $\rho=8 \times 10^{5}$.

\begin{tabular}{lcccc}
\hline Criterion & Hyperbolic passive & Sample passive & Semi-active & Active \\
\hline$J_{1}$ (peak base shear) & 0.9683 & $\mathbf{1 . 2 2 4 1}$ & 0.9618 & 0.9502 \\
$J_{2}$ (peak base moment) & 0.7504 & 0.6334 & 0.7476 & 0.7699 \\
$J_{3}$ (peak mid-span disp.) & 0.8080 & 0.6418 & 0.8024 & 0.8231 \\
$J_{4}$ (peak mid-span acc.) & 0.9937 & $\mathbf{1 . 2 9 5 8}$ & 0.9814 & 0.7941 \\
$J_{5}$ (peak bearing def.) & 0.6555 & 0.3970 & 0.8121 & 0.9370 \\
$J_{6}$ (peak ductility) & 0.7504 & 0.6334 & 0.7476 & 0.7699 \\
$J_{7}$ (peak dissap. energy) & 0 & 0 & 0 & 0 \\
$J_{8}$ (plastic connect.) & 0 & 0 & 0 & 0 \\
$J_{9}$ (normed base shear) & 0.8331 & $\mathbf{1 . 0 3 1 3}$ & 0.7792 & 0.7426 \\
$J_{10}$ (norm. base moment) & 0.7105 & 0.5294 & 0.6622 & 0.6964 \\
$J_{11}$ (norm. mid-span disp.) & 0.7351 & 0.5566 & 0.6825 & 0.7033 \\
$J_{12}$ (norm. mid-span acc.) & 0.8911 & $\mathbf{1 . 0 1 7 4}$ & 0.7894 & 0.7233 \\
$J_{13}$ (norm. bearing def.) & 0.3608 & 0.2513 & 0.4543 & 0.4829 \\
$J_{14}$ (norm. ductility) & 0.7105 & 0.5294 & 0.6622 & 0.6964 \\
$J_{15}$ (peak force) & 0.0074 & 0.0118 & 0.0109 & 0.01008 \\
$J_{16}$ (peak device stroke) & 0.6309 & 0.3821 & 0.7817 & 0.9019 \\
\hline
\end{tabular}


Table II. Evaluation criteria for the proposed hyperbolic nonlinear damper in Equations (2) - (6), with $a=1.5$ and $\rho=8 \times 10^{5}$.

\begin{tabular}{|c|c|c|c|c|c|c|c|}
\hline Criterion & $\begin{array}{l}\text { N. Palm } \\
\text { Springs }\end{array}$ & Chichi & $\begin{array}{c}\text { El } \\
\text { Centro }\end{array}$ & Northridge & Turkey & Kobe & Average \\
\hline \multirow[t]{2}{*}{$J_{1}$ (peak base shear) } & 0.9683 & 0.8313 & 0.8104 & 0.8918 & 0.8999 & 0.8339 & 0.8726 \\
\hline & [0.9619] & {$[0.8416]$} & {$[0.7792]$} & {$[0.8857]$} & [0.9039] & {$[0.8174]$} & {$[0.8650]$} \\
\hline \multirow[t]{2}{*}{$J_{2}$ (peak base moment) } & 0.7504 & 0.9761 & 0.7382 & 0.9812 & 0.9799 & 0.7283 & 0.8590 \\
\hline & {$[0.7476]$} & {$[0.9781]$} & {$[0.7081]$} & {$[0.9790]$} & {$[0.9788]$} & {$[0.6642]$} & {$[0.8426]$} \\
\hline \multirow[t]{2}{*}{$J_{3}$ (peak mid-span disp.) } & 0.8080 & 0.8656 & 0.8195 & 0.8576 & 0.7893 & 0.7339 & 0.8123 \\
\hline & {$[0.8024]$} & {$[0.7852]$} & {$[0.7753]$} & {$[0.8570]$} & {$[0.7166]$} & {$[0.6632]$} & {$[0.7666]$} \\
\hline \multirow[t]{2}{*}{$J_{4}$ (peak mid-span acc.) } & 0.9937 & 0.9907 & 0.9607 & 0.9608 & 0.9155 & 0.9440 & 0.9609 \\
\hline & {$[0.9814]$} & {$[0.8757]$} & {$[0.8956]$} & [0.8993] & {$[0.8006]$} & {$[0.9858]$} & [0.9064] \\
\hline \multirow[t]{2}{*}{$J_{5}$ (peak bearing def.) } & 0.6555 & 0.8359 & 0.4687 & 0.8317 & 0.7516 & 0.374 & 0.6529 \\
\hline & {$[0.8121]$} & {$[0.7647]$} & {$[0.5662]$} & {$[0.8532]$} & {$[0.6744]$} & {$[0.5097]$} & {$[0.6967]$} \\
\hline \multirow[t]{2}{*}{$J_{6}$ (peak ductility) } & 0.7504 & 0.8251 & 0.7382 & 0.7991 & 0.5279 & 0.7283 & 0.7282 \\
\hline & {$[0.7476]$} & [0.6959] & {$[0.7081]$} & {$[0.8276]$} & {$[0.3717]$} & {$[0.6642]$} & {$[0.6692]$} \\
\hline \multirow[t]{2}{*}{$J_{7}$ (peak dissipated energy) } & 0 & 0.5585 & 0 & 0.6151 & 0.3017 & 0 & 0.2459 \\
\hline & {$[0]$} & {$[0.4682]$} & {$[0]$} & {$[0.5674]$} & {$[0.2364]$} & {$[0]$} & {$[0.2120]$} \\
\hline \multirow[t]{2}{*}{$J_{8}$ (plastic connection) } & 0 & 0.6667 & 0 & 1.0000 & 0.3333 & 0 & 0.3333 \\
\hline & {$[0]$} & {$[0.6667]$} & {$[0]$} & {$[1.0000]$} & {$[0.3333]$} & {$[0]$} & {$[0.3333]$} \\
\hline \multirow[t]{2}{*}{$J_{9}$ (normed base shear) } & 0.8331 & 0.8677 & 0.6809 & 0.8329 & 0.8702 & 0.7507 & 0.8059 \\
\hline & {$[0.7792]$} & {$[0.8457]$} & {$[0.5970]$} & [0.8288] & {$[0.8402]$} & [0.6909] & {$[0.7636]$} \\
\hline \multirow[t]{2}{*}{$J_{10}($ normed base moment) } & 0.7105 & 0.8177 & 0.6498 & 0.8383 & 0.6385 & 0.7142 & 0.7282 \\
\hline & {$[0.6622]$} & {$[0.7984]$} & {$[0.5594]$} & {$[0.8378]$} & {$[0.5019]$} & {$[0.6560]$} & {$[0.6693]$} \\
\hline \multirow{2}{*}{$J_{11}$ (normed mid-span disp.) } & 0.7351 & 0.7893 & 0.6690 & 0.8000 & 0.6297 & 0.7417 & 0.7275 \\
\hline & {$[0.6825]$} & {$[0.7532]$} & {$[0.5797]$} & {$[0.7772]$} & {$[0.5732]$} & {$[0.6743]$} & {$[0.6734]$} \\
\hline \multirow[t]{2}{*}{$J_{12}$ (normed mid-span acc.) } & 0.8911 & 0.8777 & 0.7516 & 0.8686 & 0.8878 & 0.8791 & 0.8593 \\
\hline & {$[0.7894]$} & {$[0.8074]$} & {$[0.6895]$} & {$[0.8178]$} & {$[0.8087]$} & {$[0.8376]$} & {$[0.7917]$} \\
\hline \multirow[t]{2}{*}{$J_{13}$ (normed bearing def.) } & 0.3608 & 0.7719 & 0.4351 & 0.7823 & 0.4658 & 0.2894 & 0.5176 \\
\hline & {$[0.4543]$} & {$[0.7460]$} & [0.3929] & {$[0.7744]$} & {$[0.4045]$} & {$[0.3679]$} & {$[0.5233]$} \\
\hline \multirow[t]{2}{*}{$J_{14}$ (normed ductility) } & 0.7105 & 0.5425 & 0.6498 & 0.7232 & 0.4839 & 0.7142 & 0.6374 \\
\hline & {$[0.6622]$} & {$[0.6927]$} & {$[0.5594]$} & {$[0.7713]$} & {$[0.2204]$} & {$[0.6560]$} & {$[0.5937]$} \\
\hline \multirow[t]{2}{*}{$J_{15}$ (peak force) } & 0.0074 & 0.0096 & 0.0053 & 0.0096 & 0.0094 & 0.0071 & 0.0081 \\
\hline & {$[0.0109]$} & {$[0.0227]$} & {$[0.0084]$} & {$[0.0226]$} & {$[0.0157]$} & {$[0.0096]$} & {$[0.0150]$} \\
\hline \multirow[t]{2}{*}{$J_{16}($ peak device stroke) } & 0.6309 & 0.8004 & 0.4310 & 0.7576 & 0.7451 & 0.3696 & 0.6224 \\
\hline & {$[0.7817]$} & {$[0.7322]$} & {$[0.5207]$} & {$[0.7772]$} & {$[0.6685]$} & {$[0.5025]$} & {$[0.6638]$} \\
\hline$J_{17}$ (peak power) & - & - & - & - & - & - & \\
\hline$J_{18}($ total power $)$ & - & - & - & 一 & - & - & \\
\hline$J_{19}$ (number of devices) & 16 & 16 & 16 & 16 & 16 & 16 & \\
\hline$J_{20}$ (number of sensors) & - & - & - & - & - & - & \\
\hline$J_{21}$ (computational resource) & - & - & - & - & - & - & \\
\hline
\end{tabular}

The quantities in square brackets correspond to the evaluation criteria for the sample semi-active control strategy in [7].

\subsection{Time-history plots}

Figures 7 and 8 show the time-history plots of various response quantities for the uncontrolled building, the building with the proposed passive control and the sample passive control in [7] using the North Palm Springs earthquake. More precisely, Figure 7 presents the plots for the displacement at mid-span. The plotted quantity in Figure 8 is the base shear force in the structure. Finally, the control force generated by the control devices is also depicted in Figure 8. 


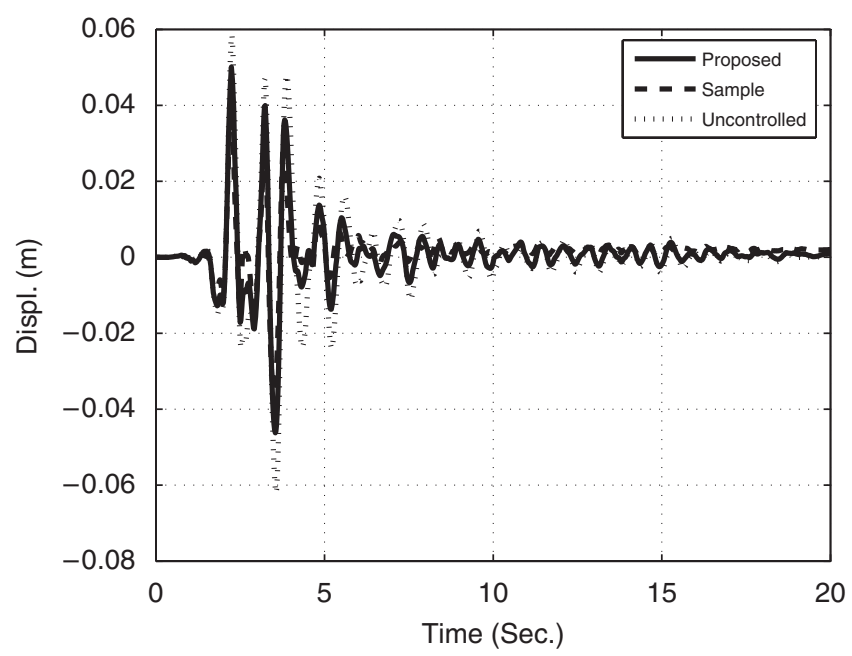

Figure 7. Time history of response of the bridge structure under North Palm Springs excitation. Displacement at mid-span for both the uncontrolled and the controlled situations.
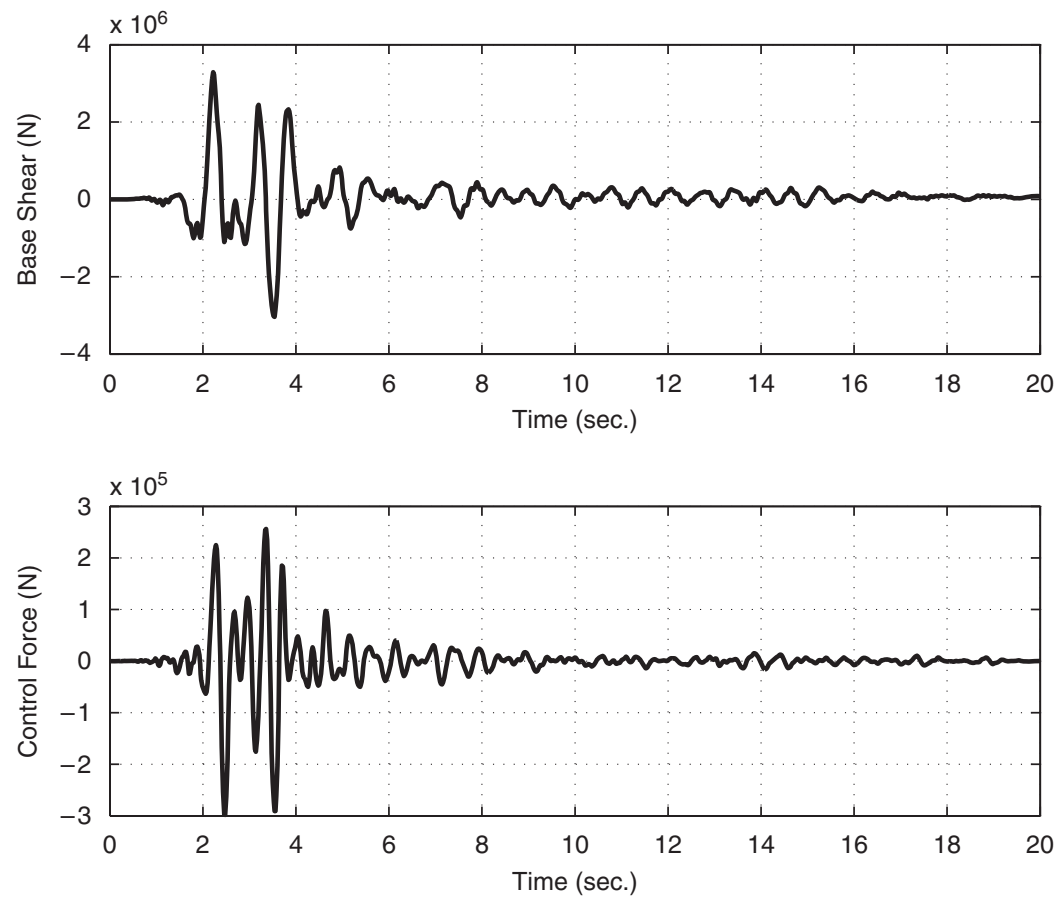

Figure 8. Time histories of the base shear force in the controlled structure (up) and control force generated by the control devices (down) under North Palm Springs excitation. 
It is observed from these figures that the controlled response quantities can be effectively reduced compared with the uncontrolled case.

\section{CONCLUSIONS}

In this paper, a new strategy has been proposed for the vibration mitigation of seismically excited bridge structures. The main feature of the proposed controller is its simplicity in the formulation, design and implementation. More precisely, the proposed control scheme is based on using a passive static hyperbolic function depending only on velocity. This function ensures energy dissipation capabilities with always bounded control force. Performance of the proposed controller has been evaluated by numerical simulations using a state-of-the-art model of a highway bridge built by the ASCE Committee on structural control. The simulation results illustrate that the peak and normed base shear, the peak and normed mid-span displacements and the peak and normed mid-span accelerations have been significantly reduced by using the proposed hyperbolic controller as compared with the purely passive isolation scheme. Since the main objective of the application has been to assess the efficiency of the concept of such stabilizing control law, it has been applied in a generic way independently of which particular actuating scheme would be available for the implementation. Finally, the performance indices have shown that the proposed hyperbolic controller behaves satisfactorily and with a reasonable control effort.

\section{REFERENCES}

1. Feng MQ, Kim J-M, Shinozuka M, Purasinghe R. Viscoeslastic dampers at expansion joints for seismic protection of bridges. Journal of Bridge Engineering 2000; 5(1):67-74.

2. Nagarajaiah S, Riley MA, Reinhorn AM. Control of sliding isolated bridges with absolute acceleration feedback. Journal of Engineering Mechanics 1993; 119(11):2317-2332.

3. Sahasrabudhe S, Nagarajaiah S. Experimental study of sliding isolated buildings with MR dampers in near fault earthquakes. Journal of Structural Engineering 1993; 131(7):1025-1034.

4. Sahasrabudhe S, Nagarajaiah S. Effectiveness of variable stiffness systems in base-isolated bridges subjected to nearfault earthquakes: an experimental and analytical study. Journal of Intelligent Material Systems and Structures 2005; 16(9):743-756.

5. Agrawal AK, Tan P, Nagarajaiah S, Zhang J. Benchmark structural control problem for a seismically excited highway bridge - Part I: Phase I problem definition. Structural Control and Health Monitoring. DOI: 10.1002/ stc. 301 .

6. Nagarajaiah S, Narasimhan S, Agrawal AK, Tan P. Benchmark structural control problem for a seismically excited highway bridge - Part III: Phase II sample controller for the fully base-isolated case. Structural Control and Health Monitoring. DOI: $10.1002 /$ stc.293.

7. Tan P, Agrawal AK. Benchmark structural control problem for a seismically excited highway bridge-Part II: Phase I sample control design. Structural Control and Health Monitoring. DOI: 10.1002/stc.300.

8. Ohtori Y, Christenson RE, Spencer BF, Dyke SJ. Benchmark control problems for seismically excited nonlinear buildings. Journal of Engineering Mechanics (ASCE) 2004; 130(4):366-385.

9. Spencer BF, Dyke SJ, Deoskar HS. Benchmark problems in structural control-Part I: active mass driver system. Earthquake Engineering and Structural Dynamics 1998; 27(11):1127-1139.

10. Spencer BF, Dyke SJ, Deoskar HS. Benchmark problems in structural control-Part II: active tendon system. Earthquake Engineering and Structural Dynamics 1998; 27(11):1141-1147.

11. Yang JN, Agrawal AK, Samali B, Wu JC. A benchmark problem for response control of wind excited tall buildings. Journal of Engineering Mechanics 2004; 130(4):437-446.

12. Caicedo JM, Dyke SJ, Moon SJ, Bergman LA, Turan G, Hague S. Phase II benchmark control problem for seismic response of cable-stayed bridges. Journal of Structural Control 2003; 10(3-4):137-168. 
13. Dyke SJ, Caicedo JM, Turan G, Bergman LA, Hague S. Phase I: benchmark control problem for seismic response of cable-stayed bridges. Journal of Structural Control 2003; 129(7):857-872.

14. Narasimhan S, Nagarajaiah S, Johnson EA, Gavin HP. Smart base-isolated benchmark building. Part I: problem definition. Structural Control and Health Monitoring 2006; 13(2-3):573-588.

15. Narasimhan S, Nagarajaiah S, Johnson EA. Structural control benchmark problem: Phase II-nonlinear smart base-isolated building subjected to near-fault earthquakes. Structural Control and Health Monitoring 2008; 15(5): 653-656.

16. Narasimhan S, Nagarajaiah S, Johnson EA. Smart base isolated benchmark building. Part IV: Phase II sample controllers for nonlinear isolation systems. Structural Control and Health Monitoring 2008; 15(5):657-672.

17. Nagarajaiah S, Narasimhan S. Smart base-isolated benchmark building. Part II: Phase I sample controllers for linear isolation systems. Structural Control and Health Monitoring 2006; 13(2-3):589-604.

18. Liu JS, Chen SL. On global stability of quadratic state feedback controlled linear systems. Systems and Control Letters 1993; 21(5):371-379.

19. Dyke SJ, Spencer BF, Sain MK, Carlson JS. Modeling and control of magnetorheological dampers for seismic response reduction. Smart Materials and Structures 1996; 5(5):565-575.

20. Ikhouane F, Dyke SJ. Modeling and identification of a shear mode magnetorheological damper. Smart Materials and Structures 2007; 16:605-616.

21. Luo N, Rodellar J, Vehí J, De la Sen M. Composite semi-active control of a class of seismically excited structures. Journal of The Franklin Institute 2001; 338:225-240. 